\title{
Adverse events related to total ankle replacement devices: an analysis of reports to the United States Food and Drug Administration
}

\author{
Karim Mahmoud $^{1}$ (D) - Sreenivasulu Metikala ${ }^{1}$ (D) $\cdot$ Kathryn M. O'Connor $^{1} \cdot$ Daniel C. Farber $^{1}$ (D)
}

Received: 3 December 2020 / Accepted: 2 February 2021 / Published online: 11 February 2021

(C) The Author(s) 2021

\begin{abstract}
Background The published outcomes of total ankle replacement (TAR) implants came from limited institutions creating observational bias. For broader perspective, we queried the Food and Drug Administration's (FDA) Manufacturer and User Facility Device Experience (MAUDE) voluntary database to explore complications reported outside published literature.

Methods The database was reviewed retrospectively between November 2011 and April 2019 using two product codes assigned to six TAR devices.

Results Among 648 relevant reports available in the database, common complications were aseptic loosening (19.3\%), infection $(18.2 \%)$, and alignment/mechanical issues (16.5\%). Others included instrument/instrumentation complications, impingement, polyethylene problems, fractures, avascular necrosis of talus (AVN), and packaging issues.

Conclusion MAUDE database revealed various patterns of device-related malfunctions that have been under-reported in published data. Despite inconsistency in the available reports, it provided opportunities for improvements in quality control, device design, and ultimately patient safety. Database would be further strengthened by more robust reporting mechanism or mandatory reporting of device-related complications.
\end{abstract}

Keywords Total ankle replacement $\cdot$ Adverse event $\cdot$ Device failure $\cdot$ MAUDE database

\section{Introduction}

Total ankle replacement (TAR) has gained wide acceptance and popularity since its introduction in the early 1970s [1,2]. Although ankle arthrodesis has been the gold standard for the management of end-stage ankle arthritis, it has the disadvantages of loss of motion at tibiotalar joint and potential risk of development of adjacent joint arthritis $[3,4]$. Studies on TAR

$\overline{\text { Level of evidence: Level IV, Case Series from Large Database Analysis }}$

Karim Mahmoud

kimo30@hotmail.com

Sreenivasulu Metikala

smetikala@gmail.com

Kathryn M. O'Connor

connor@pennmedicine.upenn.edu

Daniel C. Farber

Daniel.Farber@pennmedicine.upenn.edu

1 Department of Orthopaedic Surgery, University of Pennsylvania Perelman School of Medicine, Philadelphia, PA, USA reported superior gait patterns [5-9] with preservation of motion of adjacent joints [10]. Given these reasons, the proportion of ankle arthroplasty procedures has been increasing substantially every year $[11,12]$ and TAR has become an attractive alternative to arthrodesis in select cases. Likewise, the rates of complications and revisions are also on the rise which appear to be greater than that of total hip and knee arthroplasty implant systems $[13,14]$. However, most of the published data on the problems related to TAR devices came from individual case series that were reported by a limited number of health care facilities and surgeons. Hence, the statistics described in the publications are unlikely to reflect all the current modes of the adverse events across the national community of surgeons performing TARs and may not represent the experience of lower-volume surgeons.

In an effort to widely explore the complications related to TAR implants across the USA, we queried the USFDA's Manufacturer and User Facility Device Experience (MAUDE) database, a voluntary platform designed to report malfunctions of medical devices [15]. Using a three letter code assigned to each device in the database, the data on the available adverse events can be sorted by the year of surgery or 
manufacturer to select the reports of interest. This data is publicly available with no attached personal health information. We hypothesized that a review of the MAUDE database would be an effective method to isolate different problems related to TAR devices that may not have been reported in the published literature. A similar method has been previously implemented exploring adverse events of shoulder arthroplasty implants as well as total elbow replacement and radial head arthroplasty $[16,17]$. To our knowledge, the MAUDE database has not been previously researched to ascertain the characteristics of TAR complications.

\section{Material and methods}

Retrospective investigation of the MAUDE database [18] was performed between November 1, 2011, and April 30, 2019, to survey the reports on TAR adverse events. A manual search of the FDA's published Device Classification list detected 2 codes: NTG and HSN that were assigned to seven TAR prostheses including Scandinavian Total Ankle Replacement (STAR- Stryker, Kalamazoo, MI), Trabecular Metal Total Ankle (TMTA - Zimmer, Warsaw, IN), Vantage TAR system (Exactech, Gainesville, FL), Infinity/Inbone (Wright Medical Technology, Memphis, TN), Salto Talaris (Integra, Plainsboro, NJ), Cadence (Integra, Austin, TX), and Agility (DePuy, Warsaw, IN). All the available reports were evaluated to determine the total number of adverse events, types of adverse events, and any individual issues that were unique to a particular device.

\section{Results}

A total of 993 reports were detected in the MAUDE database during the aforementioned study period. After the exclusion of duplicate reports and non-arthroplasty reports, 648 specific events remained for final analysis. Each report typically has the model/catalog number, device problem, event date, and type followed by a brief description of the event and manufacturer narration (Fig. 1). Since the terminology used by the reporters for describing the problems was highly variable, every effort has been made by the authors to categorize all 648 adverse events into meaningful subgroups as depicted in Table 1 and Fig. 2.

Furthermore, the data has been summarized in Table 2 and Fig. 3 according to each TAR device. The most common reported event was aseptic loosening (19.3\%) followed by infection (18.2\%) and alignment/mechanical issues (16.5\%). Other reports included instrument/instrumentation issues (11.26\%), impingement problems $(9.26 \%)$, polyethylenerelated problems $(6.32 \%)$, fractures $(5.56 \%)$, AVN of talus at time of explant $(1.23 \%)$, and packaging issues $(0.46 \%)$. Incomplete reports with no available data to ascertain specific complications or adverse events were grouped as unspecified events which represented $8.33 \%$ of all reports. Two incidents of pulmonary embolism and one each of peroneal tendinosis, tibialis posterior tendinosis, allergic reaction, superficial peroneal nerve palsy, amputation, and death were also mentioned in the database. The complications of distal fibular fixation such as four reports of nonunion and one report of plate breakage were described only for the Zimmer Trabecular Metal TAR system.

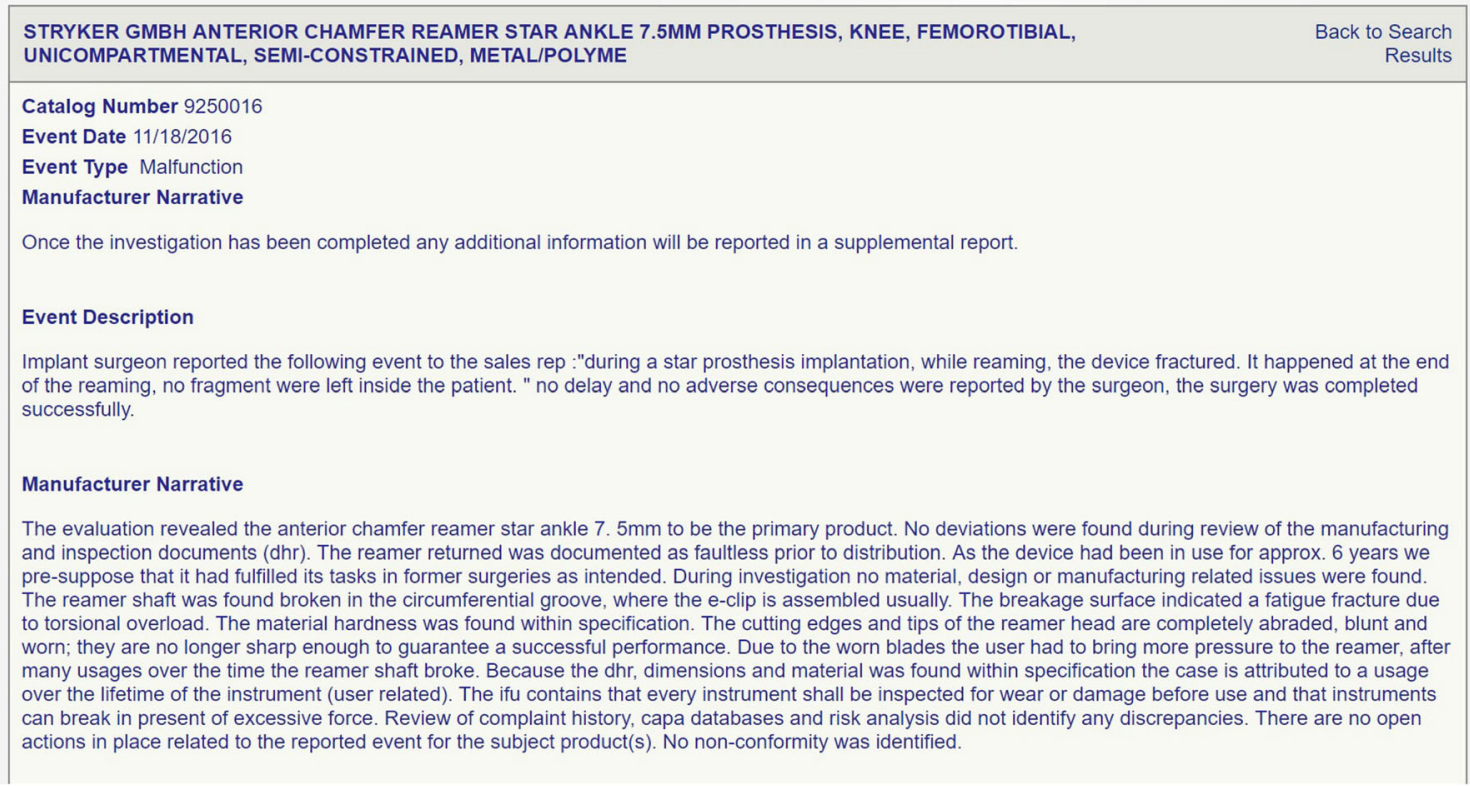

Fig. 1 Example of an adverse report with the catalog number, event date, and type followed by a brief description of the event and manufacturer narration in the MAUDE database indicating a fracture of a reaming instrument 
Table 1 Assigned subgroups for the different terms of adverse reports mentioned in the MAUDE database

\begin{tabular}{ll}
\hline Assigned subgroups & MAUDE terminology \\
\hline Aseptic loosening & Severe osteolysis \\
& Loose implant \\
& Subsidence \\
Infection & Superficial infection \\
& Deep infection \\
& Deep sepsis \\
Alignment/mechanical issues & Instability \\
& Malalignment \\
& Malposition \\
Implant/instrumentation problems & Pin/screw/drill/reamer breakage \\
& Tibial stem breakage \\
& Implant dislodgement \\
& Alignment guide problems \\
& Custom jig problems \\
Impingement & Soft tissue impingement \\
& Bony impingement \\
& Heterotopic ossification \\
Polyethylene-related problems & Gutter tightness \\
& Loose poly \\
& Small/large poly \\
& Fractured poly \\
& Poly dislodgement \\
& Poly wear \\
Fractures & Fracture of medial malleolus \\
& Fracture of lateral malleolus \\
& Periprosthetic fractures of tibia/talus \\
& Package-partially opened \\
& Expired date \\
& Late arrival of inventory \\
\hline & \\
& \\
& \\
& \\
&
\end{tabular}

\section{Discussion}

The MAUDE database of the United States FDA is a publicly available online resource that is federally funded and continually updated with the voluntarily reported individual devicerelated problems. The database can readily be explored according to the product class or device name using the designated three letter code and further researched by the year and manufacturer to locate reports of interest. Unlike published literature that depicts the outcomes for a relatively limited group of surgeons, MAUDE data provides data regarding device-related malfunctions reported by a broad range of health care professionals including community and low volume practitioners. Besides, published data may be subject to observational or selection bias as reporting authors in many cases have helped to develop various prosthetic designs. Such a possibility is rare to occur in the MAUDE database. Among the 648 descriptions in the MAUDE website, 371 were identified for STAR device, 113 for Wright Medical implants, 80 for Zimmer TM, 51 for Salto Talaris, 13 for Agility, 12 for Cadence, and eight were for Exactech implants.

A striking difference can be seen among the TAR-related complications reported in the MAUDE data versus published literature. An analysis of recently published data [19] on the intermediate-term experience with STAR devices in the USA revealed 21 implant-related issues among 138 implantations at an average of five year follow-up. They consisted of alignment problems $(38 \%)$, periprosthetic fractures $(15.2 \%)$, polyethylene fractures (6.5\%), impingement issues (3.6\%), infection $(2.9 \%)$, symptomatic cysts that required debridement

Summary of Adverse Events in the MAUDE Database

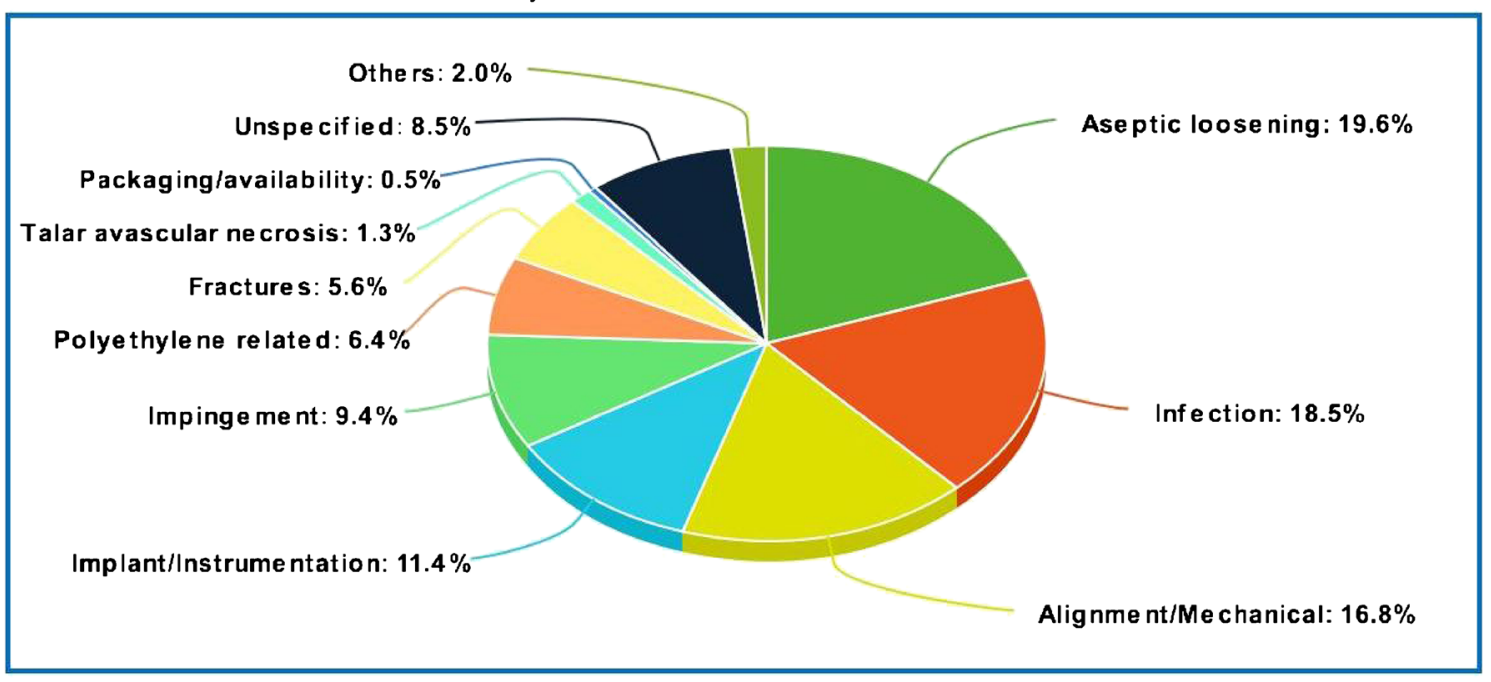

Aseptic loosening Infection Alignment/Mechanical

Implant/Instrumentation _ Impingement_ Polyethylene related Fractures

Talar avascular necrosis — Packaging/availability $\square$ Unspecified Others

Fig. 2 Summary of adverse events reported on MAUDE database 


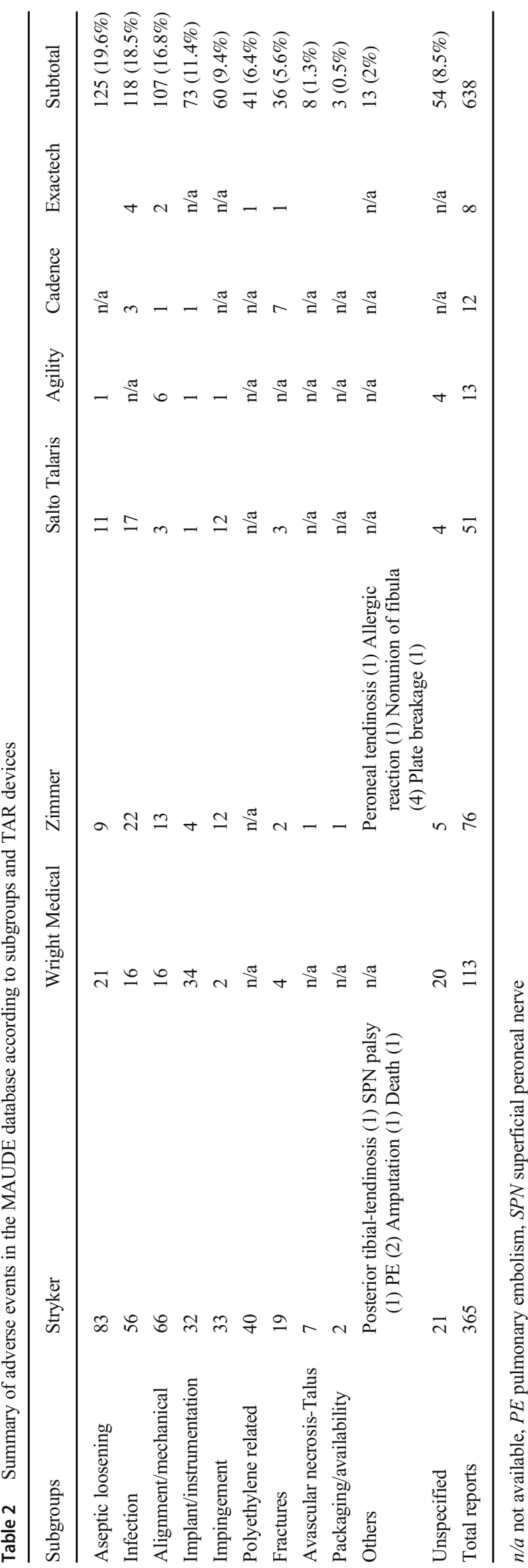

$(2.2 \%)$, and amputation (1.4\%). Similar problems were identified in the MAUDE database in addition to $8.6 \%(n=32)$ reports specifically related to dysfunction of instrumentation, and $1.9 \%(n=7)$ cases of AVN of the talus which were not mentioned in the above publication.

Similarly, the first published report using the Infinity TAR system on clinical and radiographic outcomes of 67 patients [20] with a minimum of two year follow-up disclosed two cases (3\%) each of aseptic loosening and heterotopic ossification along with one patient $(1 \%)$ each with deep infection and intra-operative lateral malleolus fracture. Results of the INBONE I prosthesis [21] that completed a minimum of four to ten years of follow-up in a consecutive series of 149 patients at a single institution displayed $9.4 \%$ failures due to cysts/ loosening (4.7\%), talar subsidence $(2.7 \%)$, and one $(0.7 \%)$ each with fracture of the tibial component, chronic impingement, and infection. No reports of polyethylene problems, periprosthetic fractures, or instrument-related issues were described in the published data with either of the above devices. Conversely, 30\% $(n=34)$ of the MAUDE adverse reports described for the above two Wright Medical TAR implants were attributed to the implant and custom jig instrumentation.

The published data on a single surgeon's initial experience [22] of 55 primary total ankle arthroplasties using the Zimmer TMTA reported $93 \%$ implant survival at 24 months of followup. Their complications were three cases of aseptic loosening, two infections, three instances of impingement problems, and one case each of malalignment, intra-operative medial malleolar fracture, and talar fracture. Another case series of 16 patients using the same implant system with a two year follow-up revealed three cases of delayed/nonunion of fibular osteotomy [23]. Unlike other TAR devices, complications of distal fibular fixation were unique to the Zimmer Trabecular Metal TAR system since it requires a fibular osteotomy. Theoretically, this lateral transfibular approach has an advantage of a reduction in the potential for vascular injury to the talus [24], although one incident of talus AVN was specified in the MAUDE database which was, once again, never reported in the published data.

Likewise, a review of 72 patients that had Salto Talaris total ankle replacement with at least a five year follow-up demonstrated $95.8 \%$ survivorship [25]. Two incidents of aseptic loosening of the tibial component and one with chronic wound infection were mentioned as major complications requiring revision procedures. Other complications reported in this study were nine cases of impingements requiring gutter debridements, one with tarsal tunnel syndrome managed by open release and posterior tibial nerve repair, and one case of symptomatic periprosthetic bone cyst treated by bone grafting and polyethylene spacer exchange. No periprosthetic fractures were specified in this publication while three such reports were reported in the MAUDE database related to the same TAR implant. 
Summary of the Main Complication of Each Implant System

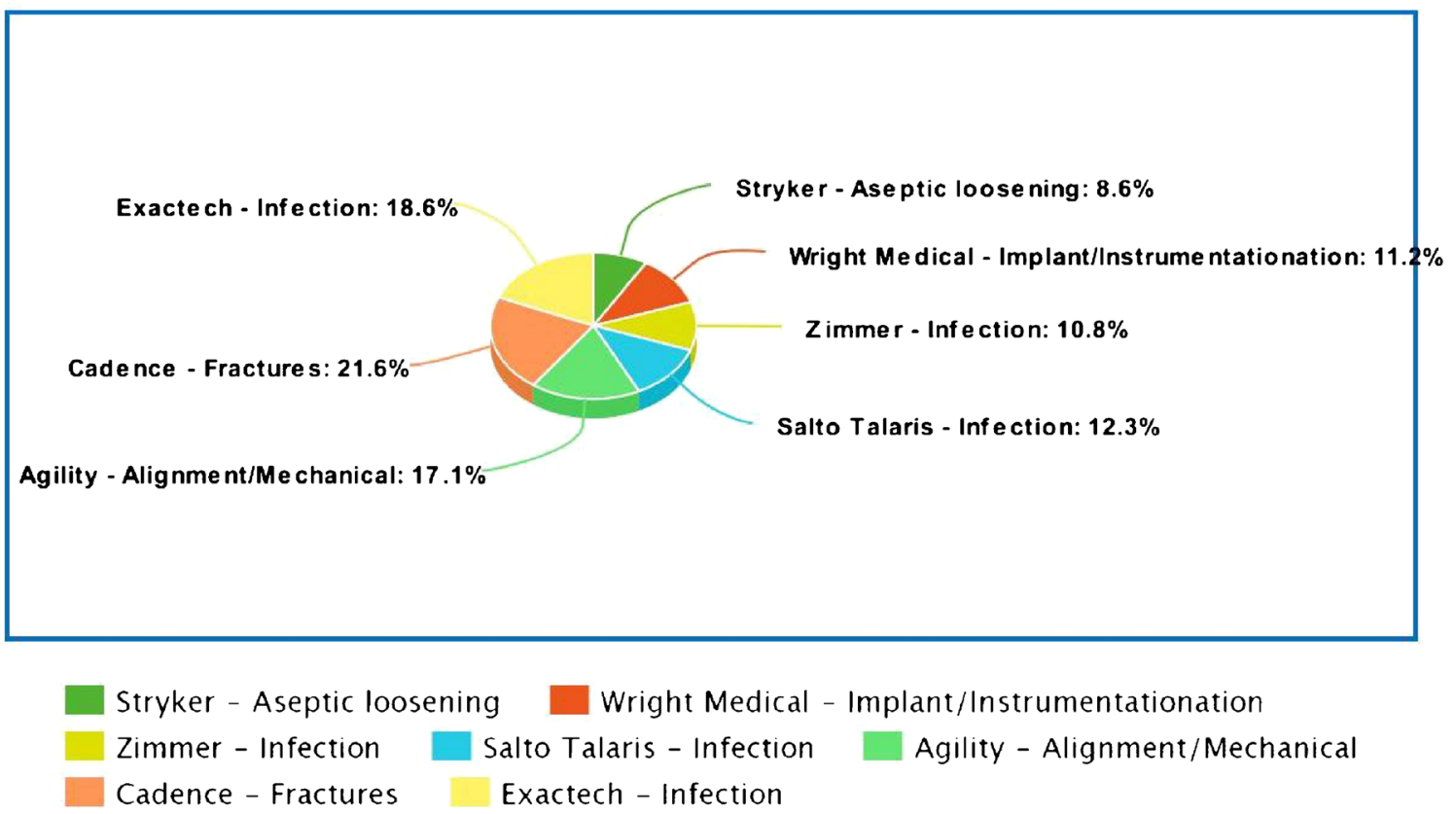

Fig. 3 Summary of the main complication for each TAR system reported on the MAUDE database

To sum up, exploration of the MAUDE database had provided insight into the various intraoperative and postoperative problems associated with multiple TAR prostheses. However, it should be noted that there are several limitations to this study. First, the terminology of the available reports in the database was highly variable. This is due to the lack of a standard template for reporting a given adverse event which led to the inconsistency of submitted data. A similar problem exists in the published literature too. Glazebrook et al. recognized this issue and proposed a simplified classification system based on the severity of complications leading to TAR failure [26]. Later on, Mercer et al. described a detailed prototype worksheet for the standardized assessment and reporting of adverse events associated with TAR systems [27]. Such a system is not available in the MAUDE website. Secondly, the absolute rate of adverse incidents cannot be determined as the total number of TAR implantations of a given manufacturer during the study period was unknown. Also, the voluntary basis of the database reporting prevents the estimation of the true incidence rates. Few examples cited in the database including pulmonary embolism, neighboring tendon and nerve pathologies, allergic reaction, amputation, and death may not be pertinent to TAR devices. Finally, as with any online database, the accuracy and completeness of the details rely on the entity that reports it. Nevertheless, MAUDE data revealed several adverse mechanisms for every TAR prosthesis that have not been described in the published literature.

\section{Conclusions}

This investigation of the MAUDE database provides insight into the spectrum of adverse events for total ankle arthroplasty compared to the published literature. The MAUDE website provides a convenient method to quickly report device-related issues by a broad range of health care professionals including community practitioners. However, the underutilization of this resource limits the utility of this information. More consistent or even mandatory reporting along with standardization of terminology would vastly improve the usefulness of this database in detecting implant problems and protecting the public.

Authors' contribution Karim Mahmoud designs study methodology, manuscript writing, data extraction

Sreenivasulu Metikala manuscript preparation, data extraction

Kathryn O'Connor designs study methodology, manuscript preparation

Daniel C. Farber designs study methodology, manuscript preparation

Data availability Not applicable

\section{Declarations}

Ethics approval Not applicable

Consent to participate Not applicable

Consent for publication Not applicable 
Conflict of interest Daniel C. Farber reports grants from Wright Medical and Arthrex, outside the submitted work. No interests to declare for the rest of the authors.

Open Access This article is licensed under a Creative Commons Attribution 4.0 International License, which permits use, sharing, adaptation, distribution and reproduction in any medium or format, as long as you give appropriate credit to the original author(s) and the source, provide a link to the Creative Commons licence, and indicate if changes were made. The images or other third party material in this article are included in the article's Creative Commons licence, unless indicated otherwise in a credit line to the material. If material is not included in the article's Creative Commons licence and your intended use is not permitted by statutory regulation or exceeds the permitted use, you will need to obtain permission directly from the copyright holder. To view a copy of this licence, visit http://creativecommons.org/licenses/by/4.0/.

\section{References}

1. Gougoulias NE, Khanna A, Maffulli N (2009) History and evolution in total ankle arthroplasty. Br Med Bull 89:111-151. https:// doi.org/10.1093/bmb/ldn039.

2. Lord G, Marotte JH (1973) Total ankle prosthesis. Technic and 1st results. Apropos of 12 cases. Rev Chir Orthop Reparatrice Appar Mot 59:139-151

3. Fuchs S, Sandmann C, Skwara A, Chylarecki C (2003) Quality of life 20 years after arthrodesis of the ankle. J Bone Joint Surg Br 85B:994-998. https://doi.org/10.1302/0301-620x.85b7.13984

4. Coester LM, Saltzman CL, Leupold J, Pontarelli W (2001) Longterm results following ankle arthrodesis for post-traumatic arthritis. J Bone Jt Surg - Ser A 83:219-228. https://doi.org/10.2106/ 00004623-200102000-00009

5. Benich MR, Ledoux WR, Orendurff MS, Shofer JB, Hansen ST, Davitt J et al (2017) Comparison of treatment outcomes of arthrodesis and two generations of ankle replacement implants. J Bone Joint Surg Am 99:1792-1800. https://doi.org/10.2106/JBJS.16.01471.

6. Pedowitz DI, Kane JM, Smith GM, Saffel HL, Comer C, Raikin SM (2016) Total ankle arthroplasty versus ankle arthrodesis. Bone Joint J 98-B:634-640. https://doi.org/10.1302/0301-620x.98b5.36887

7. Saltzman CL, Mann RA, Ahrens JE, Amendola A, Anderson RB, Berlet GC et al (2009) Prospective controlled trial of STAR total ankle replacement versus ankle fusion: initial results. Foot Ankle Int 30:579-596. https://doi.org/10.3113/FAI.2009.0579.

8. Seo SG, Kim EJ, Lee DJ, Bae KJ, Lee KM, Lee DY (2017) Comparison of multisegmental foot and ankle motion between total ankle replacement and ankle arthrodesis in adults. Foot Ankle Int 38:1035-1044. https://doi.org/10.1177/1071100717709564.

9. Singer S, Klejman S, Pinsker E, Houck J, Daniels T (2013) Ankle arthroplasty and ankle arthrodesis: gait analysis compared with normal controls. J Bone Jt Surg - Ser A 95:1-10. https://doi.org/10. 2106/JBJS.L.00465

10. SooHoo NF, Zingmond DS, Ko CY (2007) Comparison of reoperation rates following ankle arthrodesis and total ankle arthroplasty. J Bone Jt Surg - Ser A 89:2143-2149. https://doi.org/10.2106/JBJS.F.01611

11. Pugely AJ, Lu X, Amendola A, Callaghan JJ, Martin CT, Cram P (2014) Trends in the use of total ankle replacement and ankle arthrodesis in the United States medicare population. Foot Ankle Int 35:207-215. https://doi.org/10.1177/1071100713511606.

12. Vakhshori V, Sabour AF, Alluri RK, Hatch GF, Tan EW (2019) Patient and practice trends in total ankle replacement and tibiotalar arthrodesis in the United States from 2007 to 2013. J Am Acad Orthop Surg 27:e77-e84. https://doi.org/10.5435/JAAOS-D-1700526 .
13. Sadoghi P, Liebensteiner M, Agreiter M, Leithner A, Böhler N, Labek G (2013) Revision surgery after total joint arthroplasty: a complication-based analysis using worldwide arthroplasty registers. J Arthroplasty 28:1329-1332. https://doi.org/10.1016/j.arth. 2013.01.012.

14. Labek G, Thaler M, Janda W, Agreiter M, Stöck1 B (2011) Revision rates after total joint replacement. J Bone Joint Surg Br 93-B:293-297. https://doi.org/10.1302/0301-620x.93b3.25467

15. US Food and Drug Administration. Medical device databases Medical Device Reporting (MDR): how to report medical device problems | FDA n.d. https://www.fda.gov/medical-devices/ medical-device-safety/medical-device-reporting-mdr-how-reportmedical-device-problems (accessed August 7, 2019).

16. Somerson JS, Hsu JE, Neradilek MB, Matsen FA (2018) Analysis of 4063 complications of shoulder arthroplasty reported to the US Food and Drug Administration from 2012 to 2016. J Shoulder Elb Sur 27:1978-1986. https://doi.org/10.1016/j.jse.2018.03.025

17. Somerson JS, Matsen FA (2019) Timely recognition of total elbow and radial head arthroplasty adverse events: an analysis of reports to the US Food and Drug Administration. J Shoulder Elb Surg 28: 510-519. https://doi.org/10.1016/j.jse.2018.08.043.

18. US Food and Drug Administration. Medical device databases. MAUDE - manufacturer and user facility device experience https://www.accessdata.fda.gov/scripts/cdrh/cfdocs/cfMAUDE/ search. CFM

19. Loewy EM, Sanders TH, Walling AK (2019) Intermediate-term experience with the STAR total ankle in the United States. Foot Ankle Int 40:268-275. https://doi.org/10.1177/ 1071100718808743.

20. Penner M, Davis WH, Wing K, Bemenderfer T, Waly F, Anderson RB (2019) The infinity total ankle system: early clinical results with 2- to 4-year follow-up. Foot Ankle Spec 12:159-166. https://doi. org/10.1177/1938640018777601.

21. Harston A, Lazarides AL, Adams SB, DeOrio JK, Easley ME, Nunley JA (2017) Midterm outcomes of a fixed-bearing total ankle arthroplasty with deformity analysis. Foot Ankle Int 38:1295-1300. https://doi.org/10.1177/1071100717731853.

22. Barg A, Zwicky L, Knupp M, Hb H, Hintermann BH (2013) Total ankle replacement: survivorship. J Bone Jt Surg - Am 95:11751183

23. DeVries JG, Derksen TA, Scharer BM, Limoni R (2017) Perioperative complications and initial alignment of lateral approach total ankle arthroplasty. J Foot Ankle Surg 56:996-1000. https://doi.org/10.1053/j.jfas.2017.04.016.

24. Tennant JN, Rungprai C, Pizzimenti MA, Goetz J, Phisitkul P, Femino J et al (2014) Risks to the blood supply of the talus with four methods of total ankle arthroplasty: a cadaveric injection study. J Bone Jt Surg - Ser A 96:395-402. https://doi.org/10.2106/JBJS. M.01008

25. Stewart MG, Green CL, Adams SB, DeOrio JK, Easley ME, Nunley JA (2017) Midterm Results of the Salto Talaris Total Ankle Arthroplasty. Foot Ankle Int 38:1215-1221. https://doi. org/10.1177/1071100717719756.

26. Glazebrook MA, Arsenault K, Dunbar M (2009) Evidence-based classification of complications in total ankle arthroplasty. Foot Ankle Int 30:945-949. https://doi.org/10.3113/fai.2009.0945.

27. Mercer J, Penner M, Wing K, Younger ASE (2016) Inconsistency in the reporting of adverse events in total ankle arthroplasty: a systematic review of the literature. Foot Ankle Int 37:124-136. https://doi.org/10.1177/1071100715609719

Publisher's note Springer Nature remains neutral with regard to jurisdictional claims in published maps and institutional affiliations. 